\title{
Knowledge and Attitude of Dentists and Patients Toward Use and Health Safety of Dental Amalgam in Saudi Arabia
}

Hend N. Al-Nahedh ${ }^{1} \quad$ Ahmed A El-hejazi ${ }^{1} \quad$ Syed Rashid Habib², $\odot$

\footnotetext{
${ }^{1}$ Department of Restorative Dental Sciences, College of Dentistry, King Saud University, Riyadh, Saudi Arabia

2Department of Prosthetic Dental Sciences, College of Dentistry, King Saud University, Riyadh, Saudi Arabia
}

\begin{abstract}
Address for correspondence Syed Rashid Habib, BDS, FCPS, Department of Prosthetic Dental Sciences, College of Dentistry, King Saud University, P. O. Box 60169, King Abdullah Road, Riyadh, 11545, Saudi Arabia

(e-mail: rashidhabib@hotmail.com; syhabib@ksu.edu.sa).
\end{abstract}

\begin{abstract}
Keywords

- amalgam

- dental amalgam

- dentists

- health safety

- dental restorations

- filling

Objective The aim of this study was to assess: (1) the perceptions of dentists in Saudi Arabia concerning the amalgam controversy, (2) their attitude toward the ethical responsibility of patient information, and (3) patients' knowledge and attitude toward the use of dental amalgam.

Materials and Methods A total of 1,139 dentists were sampled on convenience by electronic survey. The questionnaire contained questions about the safety of dental amalgam, use of amalgam, case selection, alternate materials, and informing their patients about risks of amalgam. Also, 425 patients were sampled on convenience and information collected on their knowledge about amalgam and its acceptance in their oral cavities.

Results A total of 201 dentists and 425 patients participated in the study. A total of $60 \%$ of dentists and specialists declared it safe. A total of $32.4 \%$ (31) of general dental practitioners and $41 \%$ (43) specialists considered it a moral obligation to inform patients about the potential health risks associated with amalgam. Mercury toxicity was identified as the most common health hazard. About 57.3\% dentists and 36.2\% specialists opted for superior longevity as the principle advantage. Majority of patients (52.2\%) in Saudi Arabia had no knowledge about dental amalgam. While 23.1\% (98) had concern about poor color, 8.7\% (30) knew it contained silver while only $7.8 \%$ (27) patients were aware of its mercury content.

Conclusion Majority of dentists in Saudi Arabia found it safe to use amalgam while the patients had little knowledge about the possible issues with amalgam. It is recommended to improve public awareness about impact of mercury containing products on the environment.
\end{abstract}

\section{Introduction}

Dental amalgam remains the standard for economical restorative treatment of posterior teeth in many countries despite continued debate over the environmental problems arising

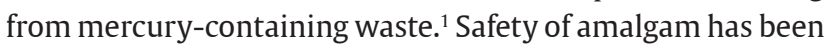
questioned since the 1840 s and continues to the present day.
However, the value of this material in public health programs remains high due to its physical properties, longevity, and ease of use. ${ }^{2}$

The main concern about dental amalgam is the mercury content. ${ }^{3}$ Following the Minamata treaty, the United Nations Environment Program issued recommendations to encourage a global phase down of dental amalgam. The primary
License terms

10.1055/s-0040-1709829

ISSN 1305-7456. 
concern was the environmental impact of continued use of dental amalgam despite there being other larger potential sources of mercury contaminants in the environment. ${ }^{4}$

While there were recent reports highlighting the issue of amalgam safety, ${ }^{5}$ the scientific literature has yet to demonstrate unequivocally the detrimental effect of amalgam on the health of patients. ${ }^{6}$ Due to the repeated reassertions of amalgam safety by health organizations and the potential environmental concerns of mercury, repeated discussions about its use occurred. This controversy coupled with increased esthetic demand by patients resulted in a marked change in the use of restorative materials during the past two decades. The continued interest by the public in the safety issue of dental amalgams and misinformation campaigns led to what appears to be a trend of amalgam replacement with resin-based composites or ceramic restorations. ${ }^{7}$ The World Dental Federation in the light of best scientific evidence available have also supported the phase down process of dental amalgam by supporting research and development of amalgam alternatives, utilization of minimal invasive measures with emphasis on preventive measures for disease control. ${ }^{4}$ While offering support to the phase down foreign direct investment (FDI) also retains the position of amalgam safety in terms of use in dental patients. ${ }^{8}$ The U.S. Food and Drug Administration categorized dental amalgam as a Class II, moderate risk substance, thereby putting amalgam in the same class as gold and tooth colored resin-based composite restorations. ${ }^{9}$

Despite these reassurances, amalgam use has declined and even ceased in certain developed countries primarily due to the environmental impact and in compliance with the Minamata treaty. ${ }^{9}$ The successful phase down of amalgam in countries like Sweden has been attributed to increased patient awareness of the environmental impact of mercury-based materials, ${ }^{10}$ suggesting that patient knowledge and attitude about the amalgam controversy can play an important role in this matter. ${ }^{11,12}$

In Saudi Arabia, there are no regulations to control the use of dental amalgams; however, guidelines by the ministry of health on the use of separators in the dental chairs, proper mercury hygiene, and disposal of amalgam scrap are enforced. Furthermore, there is a marked movement in the dental academic institutions toward increased emphasis on training dental students to use mercury-free alternatives guided by the Minamata Convention on Mercury. ${ }^{13}$

A few studies were published about the use of amalgam in the kingdom. ${ }^{13-16}$ The previous studies covered certain areas of the country mainly the capital and southern region. Furthermore, only few studies investigated the attitudes of dental patients toward amalgam. ${ }^{16}$ Hence, the objectives of this study were to assess: (1) the perceptions of dentists in Saudi Arabia concerning the amalgam controversy, (2) their attitude toward the ethical responsibility of patient information, and (3) patients' knowledge and attitude toward the use of dental amalgam.

\section{Materials and Methods}

This was a cross-sectional survey of the practicing dentists in the Kingdom of Saudi Arabia and patients being treated in different teaching hospitals and clinics of Riyadh. This study was conducted at the College of Dentistry, King Saud University, following an approval of the College of Dentistry Research Center (Reg. FR 0292) from January 2017 to March 2017. The questionnaire was pilot tested for structure and clarity of the contents on a sample of 10 dentists and patients.

\section{Dentists' Survey}

The inclusion criteria were general practitioners and advanced graduate degree holders with valid email addresses registered in the Saudi Dental society membership directory-emailing list. This database included dentists working in both public and private health institutions. The exclusion criteria included undergraduate students. A total of 1,139 active society members were sampled on convenience by emailing the self-administered electronic survey. To increase the response rate, reminder emails were sent in two stages: one in January 2017 and another in March 2017.

The questionnaire comprised of 17 close-ended questions. It comprised of two main sections. The first section included close-ended questions about the dentist's dental practices including: (1) dentists demographics: gender, age, and nationality; (2) academic background: additional graduate training degrees, current position, and years of practice; and (3) practice characteristics: practice location and type, private practice, government hospitals, health centers, or academic institution.

The second section asked the dentists' sources of information about the safety of dental amalgam, explored their opinions on amalgam use, case selection, and safety issues. Finally, the participants were asked if they think they were obligated to get the patient's informed consent. The openended question was for any additional comments or thoughts on the issue of amalgam safety from the participants.

\section{Patients' Survey}

The inclusion criteria were patients attending the hospital or private practice seeking restorative treatment. The exclusion criteria were young children, patients with linguistic barrier, and mentally challenged patients. This survey comprised six close-ended questions; three about patient demographics, two on patient information about amalgam safety, and the last on patients' acceptance of the amalgam restorations in their oral cavities. Following informed consent and using convenience sampling, 425 patients were surveyed to meet the objective of this study. The patients were interviewed by attending dentists in two major hospital complexes and three private practices in Riyadh, Saudi Arabia.

\section{Statistical Analysis}

The data obtained were entered electronically and analyzed using the Statistical Package for Social Science (SPSS Inc.; Windows version 23, Chicago, Illinois, United States). Descriptive statistics and frequency tables were generated to summarize the responses. Chi-square test was used for the statistical analyses of data in comparing 
categorical variables and the differences in distribution among the groups. A p-value of less than 0.05 was considered as significant.

\section{Results}

For the dentists' survey out of 1,139 questionnaires only 201 were received, bringing the response rate to around $17 \%$. The demographic features of the respondents are shown in - Table 1. A total of $40 \%$ of the respondents were from Riyadh area, while $60 \%$ were from the different areas of Kingdom. - Table 1 also highlighted the frequency distribution for place of practice and clinical position of the participants.

Table 1 Demographic and professional data of the dental practitioners $(n=201)$

\begin{tabular}{|l|l|l|}
\hline \multirow{4}{*}{ Gender } & & $\begin{array}{l}\text { Frequency } \\
n(\%)\end{array}$ \\
\hline \multirow{4}{*}{ Nationality } & Males & $76(37.8)$ \\
\cline { 2 - 3 } & Females & $125(62.2)$ \\
\hline \multirow{5}{*}{ Experience (y) } & Saudi & $161(80.1)$ \\
\cline { 2 - 3 } & Non-Saudi & $40(19.9)$ \\
\cline { 2 - 3 } & $5-10$ & $80(39.8)$ \\
\cline { 2 - 3 } & $11-15$ & $47(23.4)$ \\
\cline { 2 - 3 } & $>15$ & $10(5)$ \\
\hline Clinical position & General dentist & $110(54.7)$ \\
\cline { 2 - 3 } & Specialist & $33(16.4)$ \\
\cline { 2 - 3 } & Consultant & $30(14.9)$ \\
\cline { 2 - 3 } & Teaching staff & $28(13.9)$ \\
\hline Site of work & $\begin{array}{l}\text { Governmental clinic/ } \\
\text { hospital }\end{array}$ & $88(43.8)$ \\
\cline { 2 - 3 } & Private clinic/hospital & $40(19.9)$ \\
\cline { 2 - 3 } & $\begin{array}{l}\text { Government and } \\
\text { private }\end{array}$ & $12(6)$ \\
\cline { 2 - 3 } & Educational institute & $60(29.9)$ \\
\cline { 2 - 3 } & Others & $1(0.5)$ \\
\hline
\end{tabular}

Regarding amalgam safety, $60.2 \%$ of general dental practitioners and specialists declared it to be safe for both dentist and patient, while only $14.9 \%$ declared it to be unsafe for both (-Table 2). A total of 31 (15.4\%) of general dental practitioners and 43 (21.4\%) specialists considered it a moral obligation to inform patients about the potential health risks associated with amalgam use, while 24 and $34.3 \%$ of the general dental practitioners and specialists, respectively, did not consider a moral obligation to inform the patients. Majority of the general dental practitioners (43.8\%) expressed uncertainty about the question (-Table 2).

-Fig. 1 highlights the difference in responses among respondents regarding the health hazard associated with the use of amalgam. Mercury toxicity was identified as the most common health hazard.

While comparing amalgam with other restorative materials, 46.3\% (93) dentists (GDP 57.3 and specialist 36.2\%) opted for superior longevity as the principle advantage. Chi-square showed significant differences between GDP and specialists $(p<0.05$; - Table 3$)$. - Fig. 2 shows the differences in selection of alternate materials by respondents.

- Tables 4 and 5 highlighted the demographics for the patient questionnaires and their knowledge about the harmful effects of mercury in dental amalgam. About 425 questionnaires were collected from the patients attending dental clinics in different areas of Riyadh, Saudi Arabia. The majority of patients (52.2\%) had no knowledge about dental amalgam. While 22.4\% (77) were concerned about poor color, 8.7\% (30) knew it contained silver, and only 7.8\% (27) patients were aware of its mercury content (-Table 5).

Regarding attitude toward accepting dental amalgam filling, the patients were divided in their responses. - Table 6 shows the details of responses by both genders.

\section{Discussion}

The overall use of dental amalgam worldwide has declined significantly during the past two decades. Some countries like Norway, Denmark, Netherlands, Finland, and Japan successfully phased down dental amalgam despite the many challenges inherent in reducing amalgam use in dentistry. ${ }^{10}$

Table 2 Frequency of responses on amalgam safety and patient information

\begin{tabular}{|c|c|c|c|c|c|}
\hline \multicolumn{2}{|c|}{ Variable } & \multirow{2}{*}{$\begin{array}{l}\text { GDP } \\
\boldsymbol{n}(\%) \\
54(26.9)\end{array}$} & \multirow{2}{*}{$\begin{array}{l}\text { Specialist } \\
\text { n (\%) } \\
67(33.3)\end{array}$} & \multirow{2}{*}{$\begin{array}{l}\text { Total } \\
\boldsymbol{n}(\%) \\
121(60.2)\end{array}$} & \multirow{2}{*}{$\begin{array}{l}p \text {-Value } \\
0.268\end{array}$} \\
\hline \multirow[t]{5}{*}{ Opinion about amalgam safety } & $\begin{array}{l}\text { Safe for dentist and } \\
\text { patient }\end{array}$ & & & & \\
\hline & $\begin{array}{l}\text { Safe for dentist and unsafe } \\
\text { for patient }\end{array}$ & $3(1.5)$ & $1(0.5)$ & $4(2)$ & \\
\hline & $\begin{array}{l}\text { Unsafe for dentist and safe } \\
\text { for patient }\end{array}$ & $4(2)$ & $9(4.5)$ & $13(6.5)$ & \\
\hline & $\begin{array}{l}\text { Unsafe for dentist and } \\
\text { patients }\end{array}$ & $15(7.45)$ & $15(7.45)$ & $30(14.9)$ & \\
\hline & Not sure & $22(10.9)$ & $11(5.5)$ & $33(16.4)$ & \\
\hline \multirow{3}{*}{$\begin{array}{l}\text { Moral obligation to inform patient of } \\
\text { possible health risks }\end{array}$} & Yes & $31(15.4)$ & $43(21.4)$ & $74(36.8)$ & \multirow[t]{3}{*}{$0.017^{\mathrm{a}}$} \\
\hline & No & $23(11.4)$ & $36(17.9)$ & $59(29.4)$ & \\
\hline & Not sure & $42(20.9)$ & $26(12.9)$ & $68(33.8)$ & \\
\hline
\end{tabular}

aPearson's Chi-square (two-sided) significant differences between GDP and specialist. 


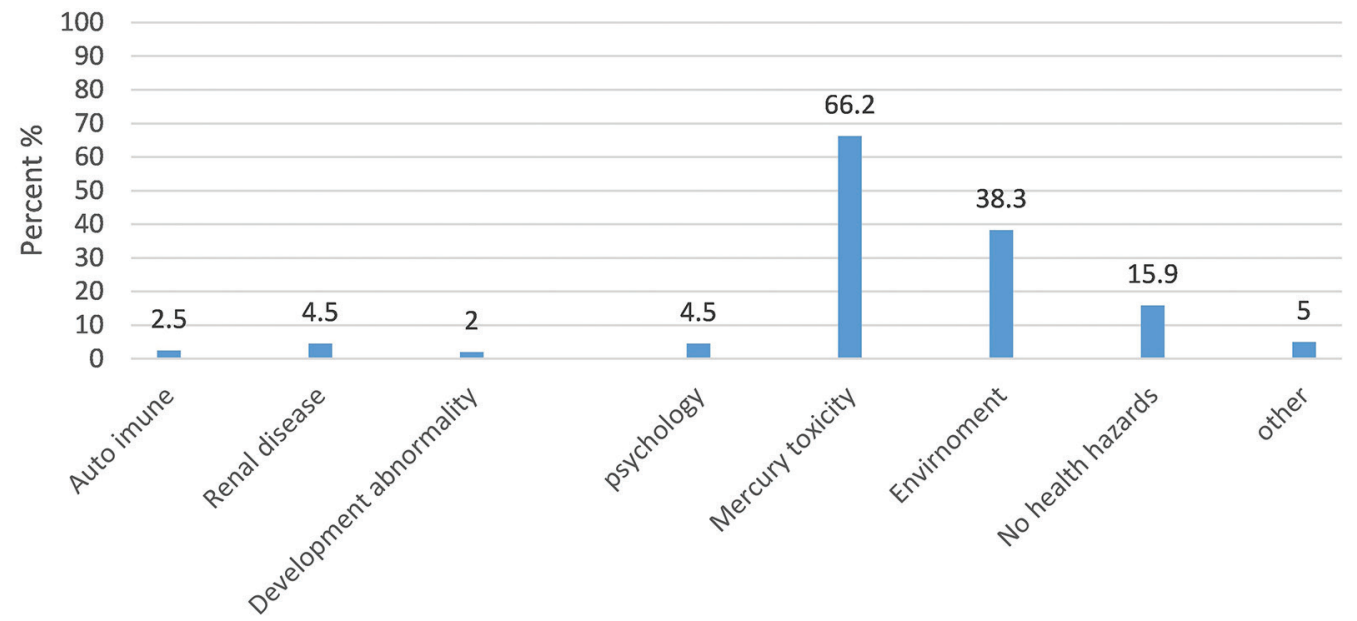

Health Hazards

Fig. 1 Health hazards of amalgam identified by responding dentists.

Table 3 Knowledge about amalgam in comparison with other alternative materials $(n=201)$

\begin{tabular}{|l|l|l|l|l|}
\hline & $\begin{array}{l}\text { GDP } \\
\boldsymbol{n}(\%)\end{array}$ & $\begin{array}{l}\text { Others } \\
\boldsymbol{n}(\%)\end{array}$ & $\begin{array}{l}\text { Total } \\
\boldsymbol{n}(\%)\end{array}$ & $\boldsymbol{p}$-Value \\
\hline Superior longevity & $55(57.3)$ & $38(36.2)$ & $93(46.3)$ & \multirow{2}{*}{0.017} \\
\hline Acceptable and less technique sensitive & $8(8.3)$ & $23(21.9)$ & $31(15.4)$ \\
\hline Fast and easy & $2(2.1)$ & $2(1.9)$ & $4(2)$ & \\
\hline Obsolete & $8(8.3)$ & $8(7.6)$ & $16(8)$ & $57(28.4)$ \\
\hline Others & $23(24)$ & $34(32.4)$ & $201(100)$ & \\
\hline Total & $96(100)$ & $105(100)$ & & \\
\hline
\end{tabular}

aPearson's Chi-square (two-sided) significant differences between GDP and specialist.

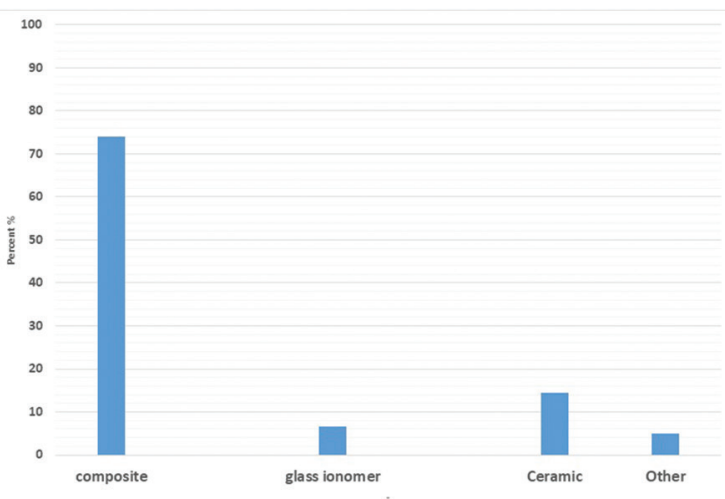

Fig. 2 Common restorative materials used as alternative to amalgam.

Countries like Sweden and Norway established a ban on amalgam use, while other countries like Denmark and Finland issued guidelines recommending that mercury-free alternatives should be the first choice for placing new restorations, except where it became difficult to place other alternative materials. ${ }^{11,12}$ In effect, amalgam was used in only $5 \%$ of restorations by 2013. This led to a significant decline in amalgam use to the point that it currently accounts for less than $3 \%$ of all the dental restorations placed in Denmark. ${ }^{10}$
Table 4 Demographic data for patients $(n=425)$

\begin{tabular}{|c|c|c|}
\hline & & $n(\%)$ \\
\hline \multirow[t]{3}{*}{ Gender } & Males & $184(43.3)$ \\
\hline & Females & $231(54.4)$ \\
\hline & Total & 415 (97.6) \\
\hline \multirow[t]{6}{*}{ Age group } & $<20$ & $86(20.2)$ \\
\hline & $21-30$ & $145(34.1)$ \\
\hline & $31-40$ & $114(26.8)$ \\
\hline & $41-50$ & $61(14.4)$ \\
\hline & $>50$ & $19(4.5)$ \\
\hline & Total & $425(100)$ \\
\hline \multirow[t]{5}{*}{ Occupation } & Students & $118(27.8)$ \\
\hline & Employed & $162(38.1)$ \\
\hline & Unemployed & $66(15.5)$ \\
\hline & Missing & 79 (18.6) \\
\hline & Total & $425(100)$ \\
\hline
\end{tabular}

This study was conducted to evaluate the impact of such global changes on the knowledge and attitudes of the dentists and patients residing in Saudi Arabia. In the current study, a smaller percentage of specialists considered amalgam to be safe compared with the GDPs, these results differ 
Table 5 Patients' knowledge about the harmful effects of mercury in dental amalgam

\begin{tabular}{|c|c|c|c|c|c|}
\hline & & $\begin{array}{l}\text { Students } \\
n(\%)\end{array}$ & $\begin{array}{l}\text { Employee } \\
n(\%)\end{array}$ & $\begin{array}{l}\text { Unemployed } \\
n(\%)\end{array}$ & $\begin{array}{l}\text { Total count } \\
n(\%)\end{array}$ \\
\hline \multirow{6}{*}{$\begin{array}{l}\text { Knowledge about dental } \\
\text { amalgam }\end{array}$} & Not much & $74(39.8)$ & 78 (41.9) & $34(18.3)$ & $186(52.2)$ \\
\hline & Poor color & $21(27.3)$ & $39(50.6)$ & $17(22.1)$ & $77(22.4)$ \\
\hline & Contains silver & $8(26.7)$ & $16(53.3)$ & $6(20)$ & $30(8.7)$ \\
\hline & Contains mercury & $6(22.2)$ & $19(70.4)$ & $2(7.4)$ & $27(7.8)$ \\
\hline & Harmful to the health & $9(37.5)$ & $8(33.3)$ & $7(29.2)$ & $24(7)$ \\
\hline & Total & $118(34.3)$ & $160(46.5)$ & $66(19.2)$ & $344(100 \%)$ \\
\hline
\end{tabular}

Table 6 Patients' attitude toward dental amalgam fillings $(n=400)$

\begin{tabular}{|c|c|c|c|c|}
\hline Would you mind if we place dental amalgam? & & $\begin{array}{l}\text { Males } \\
n(\%)\end{array}$ & $\begin{array}{l}\text { Females } \\
n(\%)\end{array}$ & $\begin{array}{l}\text { Total } \\
n(\%)\end{array}$ \\
\hline & Yes & $51(28.8)$ & $73(32.7)$ & $124(31)$ \\
\hline & No & $56(31.6)$ & $79(35.4)$ & $135(33.8)$ \\
\hline & Not sure & $70(39.5)$ & $71(31.8)$ & $141(35.3)$ \\
\hline & Total & $177(100)$ & $223(100)$ & $400(100)$ \\
\hline
\end{tabular}

from those reported by Khairuldean and Sadig, ${ }^{15}$ Udoye and Aguwa, ${ }^{17}$ and Faraj et al. ${ }^{18}$ The difference in these findings can be explained by the difference in the study populations or the population size. However, in a study investigating a similar population and sample size as the current study, Yaseen et al reported similar results in terms of GDPs (53\%) and a slightly smaller percentage of specialists (48\%) considering amalgam to be safe. ${ }^{14}$ Regarding the combined responses of GDP and specialists in this study, the majority of dentists considered dental amalgam to be safe similar to the findings of Khairuldean and Sadig, ${ }^{15}$ Udoye and Aguwa, ${ }^{17}$ and Faraj et $\mathrm{al}^{18}$ and in agreement with FDI policy statement. ${ }^{15-18}$

Despite a general agreement on amalgam safety still a significant number, primarily of specialists, believed that it is important to inform patients about the possible health risks. This conflict can be due to the need felt by some dentists to inform about the mercury content in light of the growing awareness and concern of the patients. ${ }^{19}$

A large majority of patients in the present study had no knowledge about amalgam, a small number was aware of mercury content of amalgam and an even smaller number of patients considered it to have harmful effects on the health. These findings are significantly differ from those of Khairuldean and Sadig, ${ }^{15}$ Udoye and Aguwa, ${ }^{17}$ and Doumani ${ }^{16}$ who reported a much higher percentage of patients having knowledge of the harmful effects of amalgam. ${ }^{15-17}$ These differences can be explained by the demographic data of the sampled patients since more educated patients would be more likely to be aware of current amalgam controversies. Interestingly, a large number of patients in the present study expressed concern over having amalgam placed in their mouth after the majority of them declared that they did not know much about the material. This incongruity of results could be due to increasing esthetic concerns of the patients in recent times, with greater patients requesting change of old amalgam restorations. ${ }^{13}$ The limited knowledge about amalgam being declared by a large majority of patients in this study highlights an important impediment in bringing about phase down measures in the Saudi Arabia since patient awareness has largely been attributed as the reason for effective phase down measures in countries like Sweden. ${ }^{20}$

Majority of the respondents identified longevity as the main factor for considering dental amalgam, a general agreement was observed between the GDPs and specialists. This finding is in disagreement with results published by Alkhudhairy who reported high caries risk being the main factor for opting of dental amalgam by dental practitioners. ${ }^{13}$ However, the findings reported by Faraj et al were in agreement with the current study. ${ }^{18}$

In this study, the most common reason cited by dentists for replacing amalgam was defective restoration (68.2\%); on the other hand, Alkhudhairy reported amalgam to be the most commonly (80\%) selected material for repairing defective amalgam restorations. ${ }^{13}$ Such differences depict the awareness and attitude of the dentists about the evolving scientific evidence, since the current evidence is not clear about the repair strategy for amalgam restorations most of the dentists either rely on clinical judgment, experience, and patient preference for making decisions about amalgam repair. ${ }^{21}$ The adenosine deaminase (ADA) Principles of Ethics and Code of Professional Conduct (ADA Code) addressed this issue and stated that "based on current scientific data, the ADA has determined that the removal of amalgam restorations from the nonallergic patient for the alleged purpose of removing toxic substances from the body, when such treatment is performed solely at the recommendation or suggestion of the dentist, is improper and unethical." 22

Composite was identified as the most common alternative to dental amalgam in the current study which is in agreement with Khairuldean and Sadig and Yaseen et al. ${ }^{14,15}$ However, Faraj et al reported glass ionomer to be the most preferred alternative restorative material. ${ }^{18}$ This disagreement can be 
due to a difference in the population being sampled and the economic variations across the world since composite restorations incur more expense than glass ionomer restorations.

The low response rate from the dentists is one of the limitations of the current study which makes it difficult to generalize the findings. The findings of this study suggested that in Saudi Arabia dentists find it safe to use amalgam while the patients have little knowledge about the possible issues with amalgam. It is important to improve public awareness about impact of mercury containing products on the environment. Moreover, measures should be taken to ensure proper handling, disposing of amalgam/mercury is performed by the clinics/hospitals according to FDI recommendations ${ }^{9}$ since a majority of dentists consider it safe for use.

\section{Conclusion}

Within the limitations of this study, we can conclude that dental amalgam is well accepted by dentists and patients in Saudi Arabia and the majority of dentists believe amalgam to be safe for dentists and patients alike. Superior longevity was the most commonly cited reason for amalgam selection by the study participants over other contemporary materials. Finally, the awareness of dental amalgam controversy among patients is significantly lacking, and most are either neutral or accepting of amalgam use in their oral cavities.

\section{Conflict of Interest}

None declared.

\section{Acknowledgments}

The authors would like to thank the College of Dentistry Research Center and Deanship of Scientific Research at King Saud University, Saudi Arabia, for approving this research (CDRC registration PR 0292). We would also like to thank Mr. Nasser AlMeflehi for his help with the statistical analysis.

\section{References}

1 Mitchell RJKM, Koike M, Okabe T. Posterior amalgam restorations-usage, regulation, and longevity. Dent Clin North Am 2007;51(3):573-589

2 Rathore M, Singh A, Pant VA. The dental amalgam toxicity fear: a myth or actuality. Toxicol Int 2012;19(2):81-88

3 Mortazavi G, Mortazavi SM. Increased mercury release from dental amalgam restorations after exposure to electromagnetic fields as a potential hazard for hypersensitive people and pregnant women. Rev Environ Health 2015;30(4):287-292

4 Jones DW. A Scandinavian tragedy. Br Dent J 2008;204(5): 233-234
5 Lessons from countries phasing down dental amalgam use2016. Available at: https://www.unenvironment.org/ resources/report/lessons-countries-phasing-down-dentalamalgam-use. Accessed May 24, 2019

6 Homme KG, Kern JK, Haley BE, et al. New science challenges old notion that mercury dental amalgam is safe. Biometals 2014;27(1):19-24

7 Eltahlah D, Lynch CD, Chadwick BL, Blum IR, Wilson NHF. An update on the reasons for placement and replacement of direct restorations. J Dent 2018;72:1-7

8 Dental Amalgam Phase Down2018. Available at: https://www. fdiworlddental.org/resources/policy-statements/. Accessed May 24, 2019

9 FDI World Dental Federation. FDI policy statement on dental amalgam and the Minamata Convention on Mercury: adopted by the FDI General Assembly: 13 September 2014, New Delhi, India. Int Dent J 2014;64(6):295-296

10 Bengtsson UG, Hylander LD. Increased mercury emissions from modern dental amalgams. Biometals 2017;30(2):277-283

11 Marshall SJ, Marshall GW Jr. Dental amalgam: the materials. Adv Dent Res 1992;6:94-99

12 Argou-Cardozo I, Cano Martín JC, Zeidán-Chuliá F. Dental amalgam fillings and the use of technological devices as an environmental factor: updating the cumulative mercury exposure-based hypothesis of autism. Eur J Dent 2017;11(4): 569-570

13 Alkhudhairy F. Attitudes of dentists and interns in Riyadh to the use of dental amalgam. BMC Res Notes 2016;9(1):488

14 Yaseen SM, AlShahrani I, Daghriri OH, Mufarreh M, Amer A, Tobaiqy S. Dentists perspective on silver amalgam restorations and associated hazards- a cross sectional study. Br J Med Health Res 2015;2(6):1-8

15 Khairuldean N, Sadig WM. Amalgam safety and alternative restorative materials: a cross-sectional survey among dentists. Saudi Dent J 1996;8(1):27-33

16 Doumani M, Habib A, Hatshan AR, et al Saudi patients' knowledge and awareness about mercury in dental amalgam. IOSR J Dental Medical Sci) 2017;16(8):68-70

17 Udoye C, Aguwa E. Amalgam safety and dentists' attitude: a survey among a Subpopulation of Nigerian dentists. Oper Dent 2008;33(4):467-471

18 Faraj BM, Mohammad HM, Mohammad KM. The changes in dentists' perception and patient's acceptance on amalgam restoration in Kurdistan-Iraq: a questionnaire-based cross-sectional study. J Clin Diagn Res 2015;9(4):ZC22-ZC25

19 Bamise CT, Oginni AO, Adedigba MA, Olagundoye OO. Perception of patients with amalgam fillings about toxicity of mercury in dental amalgam. J Contemp Dent Pract 2012;13(3):289-293

20 Mercury phase-out: a study of the experience of Swedish companies, Swedish Chemicals Agency -- KEMI, October 2011. Available at: https://www.kemi.se/global/pm/2011/pm-2-11phase-out-of-mercury.pdf. Accessed August 25, 2019

21 Sharif MO, Merry A, Catleugh M, et al. Replacement versus repair of defective restorations in adults: amalgam. Cochrane Database Syst Rev 2014;(2):CD005970

22 Lamacki WF. What is the ADA doing about amalgam? CDS Rev $2011 ; 104(2): 48$ 